\title{
La decoración en fachadas como determinante básico de la ar- quitectura melillense
}

\author{
Antonio Bravo Nieto
}

La ciudad de Melilla está caracterizada por la aparición a principios de siglo de un estilo decorativo en su arquitectura, que se desarrolla principalmente en las fachadas y portales, y de forma secundaria, en interiores, mobiliario, vidrieras, etc.

Cronológicamente, este decorativismo hace acto de presencia en 1909, fecha en que llega a Melilla el arquitecto catalán D. Enrique Nicto Nicto, y su etapa final podemos situarla a fines de la tercera década del siglo, cuando la tendencia racionalista prima más los volúmenes y la estructura, que lo puramente ornamental.

De acuerdo con la clasificación de Carlos Flores López, (Carlos Flores López. Gaudi, Jujol y el modernismo catalán. Barcelona, 1982) podríamos señalar que es la corriente conocida como modernista manierista o ecléctico el que inicialmente exprese su lenguaje en los edificios de la ciudad. Serán sus rasgos característicos pues, un logrado fachadismo, así como una conseguida elaboración de los portales y escaleras, manteniendo lo convencional en las plantas.

Las influencias principales vendrán dadas por el Art Nouveau y por el Secesionstil vienés, que marcará más tarde una evolución superadora del modernismo.

A este estilo, de forma gradual, sucede el llamado Novencentismo, aunque aparecen en muchas ocasiones mezclados, y que supone una reacción contra la estética modernista, al buscarse un nuevo y depurado lenguaje estructural, un poco en la línea de lo que ya se hallaba implícito en el estilo Secesión.

El paso hacia el Racionalismo se lleva a cabo a fines de los años treinta, no desprendiéndose nunca de ciertos rasgos ornamentales sin embargo. La depuración decorativa a que se llega, hace que no la contemplemos en estas notas.

$\mathrm{La}$ introducción de estas corrientes se debe en gran manera al referido arquitecto, que no se quedó estancado en ningún estilo, evolucionado a lo largo de toda su vida, aunque con unas especiales y características peculiaridades que analizaremos más adelante.

\section{Estructuración de las fachadas}

Veamos ahora la configuración de estas según el número de plantas que tengan los edificios.

En la ciudad, por regla general y exceptuando la zona del ensanche, predominan las casas bajas. 
Estas, presentan una decoración bastante simple, a base de balaustre (de tipo geométrico, vegetal, o entrelazado) con pilastras decoradas con racimos o guirnaldas. Debajo de estos elementos aparece una cornisa en forma de moldura convexa que muestra ornamento de tallos, hojas, flores o cucrda anudada.

Los vanos de ventanas y puertas están enmarcados por molduras muy características por su profusión, riqueza y variedad.

En otro tipo de casas, los marcos pueden aparecer corridos a lo largo de toda la fachada a modo de friso o bandas con abundante decoración.

Las bocas de bajantes y caños pueden rematar en cabezas de animales de fauces abiertas. En algunas ocasiones, los vanos de ventanas se completan con antepechos calados.

Por último, la fachada puede estar con su frente almohadillado.

En las edificaciones de dos plantas se repiten los temas y esquemas anteriores, pero los marcos de bajo y primer piso suelen ser diferentes, incluso varían de estilo.

Los balcones (en algunos casos corridos y con ondulaciones) tienen ménsulas de variado tipo, con una finalidad en muchos casos decorativa.

El antepecho de estos, aparece de rejería y en otros ejemplos con tramos de balaustrada o de molduras muy movidas en forma de tallos, círculos de hojas o vegetales ondulados, como los que aparecen en Cardenal Cisneros 6 o en Echegaray 16.

En otros casos, las fachadas tienen unos azulejos muy vistosos, que ocupan todo el fondo de estas, destacando mucho más la ornamentación que resalta como relieve.

Será en los edificios de más plantas $(3,46$ 6) donde encontramos la mayor riqueza y variedad compositiva, plasmada en los siguientes rasgos:

-Diferencias de marcos entre pisos.

- Los balcones están ordenados en torno a un mirador o balconada central, normalmente de tipo clásico con columnas de morfología variada, arcos, cristaleras y adornos, o extraordinariamente de forma muy original, como los enmarcados por tallos y plantas (Primo de Rivera 13). En otros casos cubre dicho mirador toda la fachada (Castelar 45).

- Las ménsulas son diversas, siendo más interesantes las de tipo zoomorfo y antropomorfo.

-A veces la casa tiene una movida coronación modernista en forma de arco con claraboya central (Ejército Español 3).

- Si el edificio forma chaflán, presenta normalmente mirador circular a base de columnitas y cristaleras, y sobre esta, un cuerpo saliente en la cornisa, o cúpula sobre tambor (Avenida 2, Ejército Español 1). El edificio llamado de la Reconquista tiene dos cúpulas muy apuntadas en las esquinas dándole gran prestancia al conjunto.

En algunos casos particulares, lo decorativo puede llegar a estructurar el edificio.

Ya de época tardía triunfará un tipo de fachada muy movida en la que priman los conceptos de volumen, y donde la decoración se transforma en esgrafiados que representan guimaldas y otros elementos tanto vegetales como geométricos, caracterizados por una acusada linealidad.

Una serie de balcones y cuerpos salientes sobre el resto de la fachada son sus rasgos característicos, y su color es muy singular, en estucado rojo o rosa oscuro y el azul 
o verde en mucha menor proporción.

Serán edificios construidos con una concepción racionalista pero que no han abandonado todavía algunos rasgos decorativos de corte novecentista.

Veamos ahora como se integran una serie de elementos decorativos, humanos, animales y vegetales en la estructura ornamental de las fachadas.

\section{Decoración antropomorfa y zoomorfa}

Es uno de los capítulos más atrayentes, y del que existen bastantes ejemplos. De raíz humana hay varios tipos principales, que se utilizan casi exclusivamente en la decoración de fachadas, siendo resultado de moldes aplicados en diversas partes de esta. Por lo general sólo está representado el rostro y la cabeza.

Tipos masculinos: son muy escasos, apareciendo uno joven con melena al estilo romántico (Fdez. Cuevas 17), varios en ménsulas, de porte bárbaro, con pelo y barba ensortijada (C. Viñals), y aunque no del todo, podemos considerar al grupo de niño y niña sentados, casi de bulto redondo (Avenida 1).

Como se puede ver, la heterogeneidad es total en los escasos ejemplos, aunque una revisión de material fotográfico de época podría conducir a otras conclusiones.

Tipos femeninos: son el grupo más abundante y variado.

Se representan normalmente jóvenes, de gran belleza y elegancia.

Podemos ver varios tipos:

-Oriental: rostro y cabeza femeninos, con rasgos orientales de estilizada belleza tanto en marcos como en ménsulas, estando muy difundido.

- Otros presentan, unas características similares por sus formas gráciles y serenidad clásica. Así puede aparecer el mismo rostro con diferentee encuadres vegetales de hojas y tallos. También están adornados con tocas y cascos muy vistosos.

Según el lugar que ocupan, son destacables las que aparecen en los enmarques de vanos, junto a otras molduras, dándose en las ménsulas las más originales, con un cuerpo de cuarto de esfera que preside el rostro, rodeado de gran multitud de entalles con hojas, a modo de nimbo, o con alas.

De bulto redondo, existían verdaderas figuras femeninas en pié, de actitudes solemnes coronando la cornisa, hoy desaparecidas, tal vez al transformarse en iglesia (G. Polavieja 2).

Es a través de estos ejemplos como comprobamos la importancia que revistió la mujer en el mundo modernista. animal.

Otro grupo es el constituido por seres de difícil encuadre, entre lo humano y lo

Destacan los genios, de los que sólo resalta el rostro en relieve, con cuernos y seria actitud (Cardenal Cisneros 10). Otros aparecen adornando la fachada como los del Teatro Perello, que muestran rasgos felinos.

En cuanto a decoración zoomorfa, hay que destacar cierta variedad, pudiendo localizarse unos tipos característicos en los elementos que configuran las fachadas.

Así se plasman en las ménsulas, a modo de sustento, bien de escala pequeña, adaptándose a sus asientos, como en el caso de monos, o de fauces de animales de pequeña factura. 
Otros serán de mayor tamaño, ocupando todo el cuarto de esfera que forma balcón y fachada, como cabezas completas de elefantes (Polavieja 46) o ave de gran tamaño con las alas abiertas (G. Mola 14) y algunos de tipo felino.

Por otro lado tenemos dos ejemplos interesantes, uno es un friso con animales fantásticos alados junto a la cornisa, a base de ladrillos vidriados, de clara reminiscencia oriental; el otro, un mirador circular adosado a una esquina, sobre cuya cornisa campea un ave. (Ambos en C. Cisneros 8 y 9).

Aparecen también como relieves, decorando la fachada, sobre todo leones de fauces abiertas (Polavieja 46), o en bocas de caños.

\section{Decoración Vegetal}

Tal vez sea la más importante cuantitativamente, así podemos constatar su aparición en:

-Enmarques de ventanas y puertas.

- Cornisas.

-Balaustradas.

- Fachada en general, balconadas y miradores.

-Antepechos.

-Ménsulas.

Es en los marcos donde podemos observar una gran variedad, a base de molduras, que se van combinando hasta la saciedad.

Normalmente se adaptan a la estructura adintelada de la puerta o ventana, sobre la cual se dispone todo el ornato a modo de encuadre.

Las formas más representativas son los tallos ondulados y hojas que se ciñen geométricamente a la superficie, en unos casos o que se derraman sobrepasando el marco propiamente dicho en otros.

Otro elemento muy utilizado son las flores, de tipo variado (girasoles, rosas, margaritas, así como otras de difícil identificación), que obedencen a un vocabulario estético muy querido por el modernismo.

También se encuentran formas poligonales y geométricas, así como encuadres de tipo frontón triangular, semicircular o partido, que sirven de asiento para la ornamentación vegetal.

Otro lugar donde encontramos elementos decorativos es en la balaustrada (que puede ser sustituida por grandes macetones, pináculos, bolas y otros elementos) y que suele ser simple, con unos tipos poco variados que normalmente adoptan la forma de pilastra, o el más interesante compuesto por círculos decorados con tallos y otros más complicados a base de calados y entrelazos.

En la comisa se emplean formas repetitivas de hojas, rosas o la de tallos estilizados.

La decoración vegetal aparece a la vez dispersa por la fachada, en balconadas y miradores, representando racimos y guirnaldas que la recorren a modo de friso o en torno a otros elementos, es aqui donde la significación del Art Nouveau, se muestra en su mayor expresión, por lo movido de su trazado y la sensualidad de sus ondulaciones.

Cuando se utiliza en antepechos, muestra calados y entrelazos, en busca de sen- 
saciones luminosas.

En las ménsulas va, bien sola, normalmente una hoja que se ciñe a la típica forma de (s), o acompañando otras molduras, en este caso más rica, como las que veiamos en las que presentan elementos antropomorfos.

Tal vez la más representativa sea la llamada casa Tortosa, en Avenida 9, donde la mezcolanza y exhuberancia de lo decorativo crea un bello conjunto en torno al balcón corrido, con molduras en torno a este que provoca a la vez sensación de horizontalidad y verticalidad en los remates; por desgracia los bajos están reformados y el conjunto pierde su unidad.

\section{Rasgos caracterizadores de lo ornamental en la ciudad de Melilla}

Señalábamos la diversidad de estilos como un rasgo básico de la obra de Enrique Nieto. Hay que resaltar ahora que estos aparecen en muchas ocasiones mezclados en un mismo edificio, lo que crea una gran variedad compositiva, siendo difícil clasificarlos como pertenecientes a una corriente u otra.

No obstante se puede sef̂alar una línca evolutiva básica en la ornamentación, según la cual, las molduras (sobre todo los enmarques de vanos) más antiguas presentarían una decoración floral y vegetal muy acusada y libre, posteriormente se iría introduciendo el concepto de lo geométrico para concluir con una linealidad total de las formas.

Unos de los rasgos distintivos de la arquitectura de Melilla es el desfase cronológico entre el desarrollo de los movimientos modernistas y novecentista, con el resto de España. Desde la fecha tardía en que se inicia el primero, 1909-10, hasta la pervivencia de la decoración novecentista durante los años treinta, e incluso inicio de los cuarenta, resta un período intermedio de intensa simbiosis creativa. Pero este desfase no va a significar un estancamiento, pues como veíamos evolucionará de unos estilos a otros, affadiendo siempre su aportación personal.

$\mathrm{La}$ intensa actividad creadora de Enrique Nieto, llevó, como ha señalado Salvador Tarragó Cid (Salvador Tarragó Cid. "D. Enrique Nieto y Nieto". Memoria de la Cátedra Gaudí, curso 1968-69. 1970). a múltiples y beneficiosas influencias, una de las cuales será la formación de una escuela de artesanos (yeseros, estucadores, ebanistas, etc.) que basándose en modelos que él había creado, extenderán la impronta de su lenguaje estético a practicamente toda la ciudad y a edificios que en ocasiones estaban realizados por otros arquitectos e ingenieros.

Otro rasgo interesante viene dado como consecuencia de la actividad de estas escuelas o talleres y su labor fuera del ensanche central.

Así, en una primera fase se construye la zona centro, posteriormente y a socaire de las campanas militares $(1909,1921)$ se crean los barrios populares, al mismo tiempo que los edificios crecen en altura y se van ornamentando.

Será en estos barrios de obreros y artesanos, normalmente constituidos por casas bajas y de una calidad no siempre óptima donde se desarrolle un peculiar fenómeno ornamental (ya veíamos como se configuraban las fachadas) que puede ser, bien el exponente de una actitud mimética o el de una expansión del gusto decorativista a las clases menos pudientes de la sociedad, que paralelamente a la construcción o mejora de 
sus casas, solicitaban la labor de los yeseros para embellecer sus fachadas, hasta fecha tan tardía como 1940, cuando este movimiento habia declinado en toda la Península.

Este fenómeno va creando una serie de combinaciones en molduras de variado matíz y gusto, y que por esta razón son catalogables.

La aparición de azulejos de ricas tonalidades cromáticas, y de rejas, sería otra faceta de este "modernismo popular", que se complementaba con la costumbre, ya casi perdida, de adomar las fachadas con macetas de plantas y flores.

Es por esta razón que el interés arquitectónico de Melilla hay que considerarlo en su totalidad.

No será por tanto, la existencia de edificios interesantes, que podríamos enumerar, lo más destacable, sino la impronta que a toda la ciudad confirió el estilo decorativo que crea Enrique Nieto Nieto, y que hace de Mclilla un conjunto original y único en este aspecto. 